This item was submitted to Loughborough's Research Repository by the author.

Items in Figshare are protected by copyright, with all rights reserved, unless otherwise indicated.

\title{
Gender, technology and the ablenational Paralympic body politic
}

PLEASE CITE THE PUBLISHED VERSION

https://doi.org/10.1080/09502386.2019.1621917

\section{PUBLISHER}

(c) Taylor \& Francis

\section{VERSION}

AM (Accepted Manuscript)

\section{PUBLISHER STATEMENT}

This is an Accepted Manuscript of an article published by Taylor \& Francis in Cultural Studies on 2 Jun 2019, available online: https://doi.org/10.1080/09502386.2019.1621917

\section{LICENCE}

CC BY-NC-ND 4.0

\section{REPOSITORY RECORD}

Pullen, Emma, and Michael Silk. 2019. "Gender, Technology and the Ablenational Paralympic Body Politic". Loughborough University. https://hdl.handle.net/2134/38332. 


\title{
Gender, Technology and the Ablenational Paralympic Body Politic
}

\begin{abstract}
The Paralympic games is a pedagogic pervasive, political, powerful, and 'popular' cultural site where the heightened visibility of disability bring into being specific forms of disability as they articulate within cultures, institutions and practices. Regarded as a 'positive charge' by Stuart Hall, the Paralympics intends to challenge the devalued disabled body politic of typical disability representation. This has been stimulated by the entry of Channel 4 as the UK Paralympic rights holders in 2012 which has seen greater media coverage of certain technologically enhanced cyborgian parasport bodies and an emerging celebrity / sexualised disability culture. This contemporary moment in disability representation provides a compelling space in which to (re-)address the gendered nature of hyper-visible Parasport hybrids, their potential to disrupt 'normative' relations of power, and, the wider impact on disability politics in a neoliberalised culture of widening and affective circuits of bodily inclusion and control. Drawing on an integrated content and textual analysis of 90 hours of Paralympic programming from the Rio 2016 Games we highlight two emblematic segments so as to enhance our appreciation of contemporary disabled politics as it intersects with gender, technology and nation. We analyse these emblematic segments at the intersection of critical disability studies, cultural studies and sport, using Mitchell and Snyder's (2015) concept of ablenationalism to highlight the extent certain technological capacitated parasport bodies perform gendered representational work as part of the seductive apparatus of neoliberal microgovernance suggestive of an emerging ecology of disability-gender relations. In doing so, we highlight the Paralympic contradictions and interrogate the assumed 'positive charge' of the contemporary (re-)presentation of disability.
\end{abstract}




\section{Introduction}

In the UK at least, the 'elevation' of the Paralympics from pastime to spectacle (Howe 2008) has, in part, been stimulated by the entry of Channel 4 (C4) as Paralympic rights holders in 2012 (see Walsh 2014). C4 brought a level of ambition for Paralympic broadcasting that was, in the words of their former Disability Executive Alison Walsh, at 'a whole new level' from previous events (Walsh 2014, p. 27). With blanket coverage, slick promotional trailers, dramatic backstories and 'edgy' coverage as an overarching frame for Paralympic representation in the United Kingdom (see Pullen et al. 2018), we find ourselves in a moment in which we can ascertain a heightened, if fleeting and ephemeral, hyper-visibility of disability on television. This is important given there exists potential for such coverage to challenge the stereotypical framing of mediated disability: helpless or passive victims; vulnerable, pitiable and childlike dependents; 'supercrips' predicated on inspirational stories of determination and personal courage to overcome adversity; as asexual; as less than human villain, freak show, or exotic; as new folk devil (fraudulent, not disabled) and thereby less deserving; or, as unable to participate fully in everyday life (Barnes and Mercer 2010, Briant et al. 2013, Jackson et al. 2015). Indeed, as opposed to a failing, incomplete, inferior and devalued disabled body politic (Shildrick 2006), the display of the courageous and triumphant Paralympic body was regarded as a 'positive charge' by Stuart Hall in his last interview (Jhally 2016). ${ }^{1}$

Within this article, we begin to unpack the hyper-visibility of disability in, and through, Paralympic media coverage in the United Kingdom. Whilst critically acclaimed, C4's coverage has fostered debate in the academic community over representations that tend to foster established hierarchies of disability acceptance (see Silva and Howe 2012), and an emphasis 
on certain, selected, (cyborgified/technocratic), technologically enhanced para-sport bodies (Howe 2011, Silva and Howe 2012): the 'superhumans'. Elsewhere we have argued that this may marginalise those with other forms of disability — athletes with cerebral palsy and severe impairments whom are deemed less marketable and media-friendly_ and engender an ableist, neoliberal, disabled body politic (see Pullen et al. 2018). For us, the hyper-visibility of disability provides for an important intervention into how specific forms of disability come into being and articulate with specific cultures, institutions and practices (Diedrich 2005). Indeed, whilst there has been attention on the increasing prominence of the technologically enhanced disabled body (see Howe 2011, Howe and Silva 2017) and an ablenational framing (see Pullen et al. 2019) there has been sparse scholarly consideration (save for a mere handful of studies, for instance, Schell and Rodriguez 2001, Buysse and Borcherding 2010) on the complex relationships between technology, disability and gender.

To begin to fill this knowledge gap, our interests in this paper are on the representation of gender as it articulates with the technologically enhanced 'cyborg' bodies of para-athletes. Through consideration of para-sport bodies as embodied 'hybrids' in the Paralympicsthrough the fusion or reconstruction of the material body with forms of technology such as high-tech prosthesis and mobility technologies - we are interested in the gendered nature of such bodies and their potential to disrupt 'normative' relations of power (Haraway 1991). To do so, we focus on the relations of gender and technology as intertextually constituted and represented in distinctly different ways through two emblematic exemplars from Channel 4's coverage of the Rio 2016 Olympic Games. In the balance of the paper, and through these examples, our discussion centres on the emerging ecology of neoliberalised gender-disability relations as it articulates with the national and the symbolic in Paralympic representations. In this sense, we develop our understandings of the implications of emerging forms of gendered 
disability representation within the Paralympics for wider disability politics so as to provide important insights into the evolving relationships between bodies, selves and representations in the contemporary conjunctural moment.

\section{Disability, Gender and the Paralympic Games}

Scholars working at the intersection or disability and gender have explored the multiple and intersecting disciplinary boundaries that have long policed disabled bodies gendered and sexual subjectivity (see Garland-Thomson 2002, 2017, McRuer 2006, 2017). The mutually constitutive systems of compulsory able-bodiedness, compulsory heterosexuality, normative aesthetics and functionality (McRuer 2006) have constructed a representational history marked by an almost complete absence of a gendered disabled body. Indeed, disability has been viewed as 'problem' (medically and socially) in the construction of both masculinity and femininity, with masculinity being inextricably bound to ableist ideologies of physicality, autonomy and power (Shuttleworth et al. 2012) and femininity to 'normative' aesthetics of beauty, both mediated by functionality with regard to sexual practices (Shakespeare 1999). Despite gendered subjectivity being contingent to the degree and form of impairment and varying cultural and historical frameworks (Gerschick 2000, Shuttleworth et al. 2012) the dominant representation of disability has been one of 'asexual objectification' (Harlan 1988).

Contemporary Parasport coverage may well add some nuance here. The 'supercrip' is the most pervasive narrative frame (Silva and Howe 2012), with the athlete heroically fighting (through individual and internal motivation) against their disability, exceeding or moving beyond disablement and achieving success (as measured against ableist benchmarks of functionality) (Kafer 2013). Whilst the manifestation of this representation is nuanced across different representational contexts (Schalk 2016), this narrative has been used to market the Paralympics 
as a site of disability 'exceptionalism' (Mitchell and Snyder 2015). Whilst there exists something of a scholarly lacuna on the representation of gender, technology and disabled body politics, research on the dominant representation of the able-bodied female sporting body is well established. Reviewing some 20 years of scholarship, Bruce (2013) suggested major patterns of able-bodied sport coverage comprise: gender marking (only the women's event is marked), compulsory heterosexuality (privilege afforded to those who fulfil heterosexual gender rules while silencing lesbian identity), appropriate femininity (physical and emotional characteristics that mark women as different from men), infantilization (representation as nonthreatening girls), sexualisation (idealized sexual attractiveness), a focus on non-sport related aspects (wife, personality, physical appearance), and ambivalence (representations that oscillate between valorisation and trivialisation) (Bruce 2013). Research however on para-sport coverage is sparse, and the evidence base relatively weak; somewhat building on Schantz and Gilbert (2001) the articulation between gender, technology and disability is an important area that requires further research.

In contradistinction to the emphasis on aesthetic form, sexual attractiveness and the sexualisation of able-bodied female athletes as sexual object (e.g. Bertling and Schierl 2008), there has been a small body of work that suggests the para-athlete is enfolded into the 'asexual objectification' (Harlan 1988) of typical disability representation (Léséleuc et al. 2010, Schell and Rodigruez 2001, Schell and Duncan 1999, Hardin and Hardin 2005). These scholars have demonstrated the extent the asexual/genderless body is framed via a process of 'infantilization' or 'trivialization' with portrayals of a passive child-like dependency and a lack of autonomy (Leseleuc et al. 2010, Ferri and Gregg 1998). Here the notion of femininity becomes redundant either through representations of being 'locked in a perpetual adolescence' (Weinberg 1988, p. 274) or through ambivalent representations (Ferri and Gregg 1998). The emphases on 
aesthetics and modes of 'beautification' associated with the representation of able-bodied athletes are, it is argued, all but absent in the images of para-athletes reflective of a cultural industry that views femininity and disability as incompatible (see Claydon 2014). However, and in concert with the encroaching commodification of the Paralympic spectacle (see Howe 2008), anecdotal evidence from the London 2012 Paralympic Games is more suggestive of a gendered and sexualised celebrity culture not overly dissimilar from able-bodied sporting culture (at least in the UK). With FHM magazines' 'Hottest Female Paralympians', the Daily Mirror's 'Sexiest Female Paralympians and social media sites Pinterest and Facebook displaying 'Paralympian Babes' and 'Paralympian and Paratriathlon Babes' respectively, important questions become apparent around narratives of disability, sport and sexuality, the ideologies of heteronormativity, compulsory heterosexuality and compulsory able-bodiedness. We need to be greater attuned to both the invisibility of sexual pleasure/disability (e.g. Tepper 2000) and the display and sexualisation of (selected, commodified) disabled bodies through the Paralympic spectacle, especially as this articulates with forms of technology and gendered relations.

There exists a more sophisticated representational history of the gendering of the male parabody due, in part, to the long affinity between war, militarization, disability and the Paralympic Games leading to a greater visibility of the male disabled body (Batts and Andrews 2011). In the contemporary moment, through rehabilitation programmes such as the USA's Paralympic military programme and Wounded Warriors, Canada's Soldiering On, the Australian Defence Force Paralympic Programme and the Battle Back programme in Great Britain (and the emergence of the Invictus games for wounded service personnel) soldiers injured in conflict have been fast-tracked into their country's Paralympic training programmes — sport once again (as it was when Guttman rehabilitated soldiers with spinal cord injuries following the second 
world war) being seen as important in attempting to re-build the lives of military personnel who have endured life-changing trauma (Brittain and Green 2012). Narratives of cyborgified heroic returning soldiers and 'terror' victims have dominated recent coverage (see Crow 2014). With Batts and Andrews (2011), the new subjectivity of the elite male soldier/athlete--as a symbol of both military and sporting constituencies-is far from benign and apolitical; it is a malleable site upon which contemporary cultural meanings and political demands are inscribed and mobilized. Indeed, this coverage, whilst further marginalizing those furthest from cyborgification (Howe 2011) is symbolic of the (re-)masculinization of the male disabled body through rehabilitation. Indeed, as Barounis (2009) claims, disability sustained through war (and other high risk 'masculinising' activities) operate to both simultaneously emasculate and reclaim masculinity, with injury and disability seen as the 'logical extension of masculinity's excess' (Barounis 2009, p. 55). Thus, in this case the process of rehabilitation - often through sport - is not viewed as a failed masculinity per se but a (re-)claiming of an emerging form of resilient masculinity. This is further compounded by the historical use of high-tech prosthetic technology in the rehabilitation of injured servicemen, that is often read as a surface extension of masculine discourse articulating strength, power and engineering transformation; 'allowing men to materially extend dominant masculine subject positions and modes of cultural performance [through] a 'carbon fibre masculinity’ (Hickey-Moody 2015, p.146).

The Paralympic spectacle then provides a compelling cultural space through which to explore technology, gender and contemporary disability body politics. It has certainly been the case that recent shifts in Parasport media coverage could present a challenge to stereotypical representations of gender and disability. Certainly, the relatively recent and palpable shift in the style of broadcasting and promotion of the Paralympics in the last decade - as indicated earlier, especially in the UK following Channel 4's entry into the marketplace-intends to 
challenge such representations and increase the visibility of disability; both on television through increased coverage (Walsh 2014), and the wider print media, for instance, ESPN magazines annual 'Body Issue' that presented overtly gendered and sexualized images of successful Paralympians (Weaving and Samson 2018). Indeed, building on discussion above regarding the emergence of a sexualized/celebrity disability culture, a number of iconic disability bodies have emerged across popular culture. Aimee Mullins, a successful model and former track and field athlete celebrated for her feminine identity vis-à-vis the use of prosthesis (Dolezal 2017) is one example, although most iconic is that of Oscar Pistorius, prior to his famed conviction for murder of his girlfriend, Reena Steemkamp. Both Mullins and Pistorius's internationally recognised disability celebrity status was, in part, down to a disability transcendence via carbon fibre prosthetic technology - the embodiment of a celebrity 'supercrip' - compounded by their 'breakthrough' into a cultural realm that privileged the normative neoliberal body politic (Ellis and Goggin 2017). Whilst, for Pistorius, his highly functional prosthesis sporting body stimulated a global debate around the legitimacy of his disabled identity and participation in able-bodied sport (Swartz and Watermeyer 2008), both Mullins and Pistorius iconic status pose interesting questions regarding the cultural dynamics of the sporting prosthesis body.

Described as a 'prosthetic aesthetic', the emergence of this disability/celebrity culture has been viewed as a new sensibility toward the disabled prosthesis body (Tamari 2017). Here the Paralympics - a powerful cultural agent and mediator in constructing and transmitting highly affective images and vicarious experiences disability (Elliot 2003) - captures this cultural moment in the hyper-visible display of technologically enhanced para-sport bodies (Pullen et al. 2019). Termed 'cyborg', 'posthuman' and 'technotopic', this form of disabled body has received much critical attention (see Balsamo 1996, Kirkup et al. 2000, Cherney 2001, Siebers 
2008, Howe 2008, Haraway, 1991). Previously deemed by Haraway (1991) as potentially emancipatory in the deconstruction of gendered and ableist relations of power, more recently, scholars such as Kurzman (2001) and Kafer (2013) have critiqued the often universalised and generalised deployment of 'cyborg' to describe all technologically augmented disabled bodies. With Kafer (2013), the cyborg has become locked to a particular body in a specific technological and socio-political moment, removing it 'from the realm of the political' (p.106). Indeed, cyborg subjectivity articulates within the boundaries of political, social and economic forces, privileging the inclusion of certain kinds of bodies and identities as potential cyborgs. As Kafer (2013) notes, moving cyborg discourse forward requires a careful consideration of political and cultural contexts, institutions, texts and images, and a recognition that the body is always political.

This has been echoed by critical disability scholars who remind us that the disabled body is always materially and discursively (re-)constituted in response to its position within a biopolitical context (Mitchell and Snyder 2015, Puar 2017). As Puar (2017) reminds us, disability is not fixed, but a discourse that is constantly negotiated in response to: the economic trajectories of neoliberalism ${ }^{2}$ and market relations (and uneven distribution of resources); evolving infrastructure and definitions of accessibility; emerging mobility technologies, supports and prosthesis; and neoliberal discourses of inclusion and diversity.

With disability scholars, Mitchell and Snyder (2015), the biopolitical management of disability in the context of neoliberalism has shifted from the social and institutional exclusion of people with disabilities to regulated forms of inclusion that invest particular subjects with forms of citizenship. Indeed, certain forms of impaired bodies can now be targeted by a wealth of markets and industries (e.g. commercially driven medical and surgical interventions, 
prosthesis, and mobility technologies) that provide support and supplementation for body enhancement, devised around culturally ideal forms of neoliberal embodiment (functional, productive, able, and aesthetically pleasing) (Mitchel and Snyder 2015), but of which provides greater access to - and inclusion within - neoliberal economies. Under such conditions, disabled bodies that fall between 'able' and 'disabled' states and with access to disability markets can become productive 'normatively' disabled bodies through (re-)construction closely aligned to neoliberal markers of successful embodiment (Mitchell and Snyder 2015).

Considering the biopolitical context, contemporary disability discourse goes beyond able/disabled binaries. Here we turn to the work of Puar (2017) who mobilises the terms 'debility' and 'capacity' to theorise the transformative materiality of bodies in neoliberal affect economies. Puar (2017) considers a form of 'triangulation'; one that theorises how the control of disabled bodies works through states of embodied capacities, agency and affect, yet, hinges on material relations, identity politics, and economic power. For instance, Puar (2017) claims, despite some bodies being recognised as disabled, the nature of their impairment, economic opportunism and access to body enhancing / disability industries allows for bodily capacitation and thus successful inclusion within ableist and neoliberal structures and systems. Relatedly, for many bodies, the uneven distribution of resources, lack of access to healthcare, and racialised and nationalised discourses, structures forms of debilitation despite being recognised as able-bodied.

Theorising disability through debility and capacity highlights how some (disabled) debilitated bodies are able to be technologically capacitated - to become, following Kafer (2013), cyborgs - and can thus be transformed into bodies that meet the demands of a neoliberal citizenship (productive, functional, enhanced capacity and aesthetically pleasing) and folded into 
neoliberal economies for on-going control. Disrupting traditional able/disabled binaries, Mitchell and Snyder (2015) and Puar (2017) consider the generative properties of the disabled body and the conditions that make forms of material embodiment - and transformation - at one and the same time, possible and impossible.

It is at this juncture we can begin to explore the gendered and technologized representations of the Paralympics. Mitchell and Snyder (2015) term successfully capacitated disabled bodies as the 'able-disabled' and highlight the extent these bodies, whilst gaining entrance into neoliberal economies through circuits of bodily inclusion, perform 'representational work as a symbol of expansive neoliberal inclusion efforts' (Mitchell and Snyder 2010, p.116) celebrated and valorised as symbols of diversity, equality and success. Here the Paralympics is writ large, as an event in which (celebrated and cyborgified) athletes with disabilities represent the nation. An emblematic exemplar of what Mitchell and Snyder (2015) would suggest as ablenationalism (Mitchell and Snyder 2015); a cultural strategy that propagates rights-based equality discourses by making visible hyper-capacitated disabled bodies (select hyper-visible para bodies) as 'effectively and normatively disabled' within the cultural sphere (Mitchell and Snyder 2010, p.116).

As such, in holding together the biopolitical management of disability, gender, technology and neoliberal (national) inclusionary 'logics', the representation of the Paralympics become an extremely important, pedagogic pervasive, political, powerful, and 'popular' (in Stuart Hall's sense of the word) space through which to explore contemporary disabled body-politics. It offers a unique, if not pre-eminent, site from which to explore disability inclusion through the often technologically capacitated bodies of Para-athletes; one that highlights the intersection of the material and social construction of disability that bring into being specific forms of 
disability. Situated as a global sporting and national disability inclusion project, Paralympic success is driven by the increasing approximation to able-bodied sporting norms often manufactured through the technologicalization of disability (Howe 2011) made possible by expanding neoliberal economies. Whilst scholars focusing on Paralympic representations have identified the extent the technologically capacitated body is viewed as the hallmark of Paralympic representation, especially those deemed 'supercrips' who tell inspirational stories of overcoming dis-ablement gaining the most media attention (Howe 2011), there has yet to be a focus on how such hierarchies operate within, and are mobilised through, the biopolitical management of the disabled body-politic as it intersects with the materiality of the body; gender, nation and technology.

\section{Methodological Approach}

To enable us to provide a robust empirical knowledge base centred on para-sport and the representation of disability, gender and technology, our methodological approach was integrative, bringing together document analysis (e.g. promotional materials, broadcast plans, websites), elite interviews, quantitative content analysis and qualitative textual analysis. ${ }^{3}$ The data in this paper is mostly taken from the textual analysis of the Channel 4-official UK Paralympic Broadcaster-2016 Rio Paralympic Games of all 90 hours of Paralympic programming over 9 days broadcast but these data were supplemented with a quantitative analysis that captured manifest elements of the text. Given the scale of the dataset the quantitative content analysis was conducted by a team of four coders and took the broadcast segment as the unit of analysis and coded into three types of segment: live sport (resulting in 274 unique segments), backstory feature (50 segments) and studio chat (229 segments), which capture the main ways in which Paralympic sport is brought to viewers. The textual analysis 
was conducted in two phases and grounded within existing disability and Paralympic literatures. The first phase included a complete reading of the broadcast material via a systematic process that identified and split segments of text for analysis. This provided a way to manage the dataset in the first instance and provide a framework to conduct further readings at specific points. Johnson et al.'s (2004) four dialogical moments of interpretation was used in the analysis and was adapted to suit the textual form providing a method for structural and intertextual readings. This included a process of: coding elements of the text and its operation within the wider structure of the text (e.g. operating as a promotional tool, live sport action, narrative form); recording visual representation, production aesthetics, frequency; identifying underlying narrative structures; and, identifying discursive elements as it is contextually positioned with the text. Following the first phase, particular interesting segments and elements were discussed with colleagues familiar with the dataset providing a point of reflection in the interpretive processes of textual analysis and a point of entry for the second textual reading. The second phase included a more focused approach and a process of 'meaning condensation' (Coffey and Atkinson 1996). In this phase key instances and elements within the wider text were given further attention, narrowing the scope and depth of the analysis and establishing links with academic work. Whilst analysis is based on an in depth reading of emblematic broadcast segments, we locate this within the quantitative data and draw throughout on understandings from the wider project and the conjunctural Paralympic/cultural moment in which the broadcasts sit.

\section{Unpacking the Paralympic Body Politic}

The two emblematic segments that we draw upon in our discussion were of significant importance for the broadcaster in narrating their entire broadcast (see Pullen et al. 2018). Both segments were 'promotional athlete films'; vignettes that featured select athletes and which 
were repeated a number of times throughout the broadcasting (varied in format but with the same underlying narrative and production value). These films held high production value, aesthetic qualities and affective dimensions; the intention being to make (hyper-)visible the disabled body, challenge dominant disability narratives and interpolate audiences with the storied backgrounds of celebrated para-athletes (see Pullen et al. 2018). The vignettes we unpack were so chosen given they focus on two of the most celebrated British Paralympians and given they are emblematic of the wider coverage, of broadcaster intent and of the nuances in the gendered, technologized, neoliberal disability body-politic inherent in Paralympic representations. The first focussed on the above knee double leg amputee Richard Whitehead, a Great British athlete who is classed as a double leg amputee and competes in the track and field athletics over the $100 \mathrm{~m}$ and $200 \mathrm{~m}$ sprint where he has won a number of gold medals in both the 2012 and 2016 Paralympic Games. The second text is focussed on Ellie Simmonds, a Great British swimmer with the condition achondoplasia (commonly known as dwarfism), and, similar to Whitehead, well known for her success, having won a total of 8 Paralympic medals across multiple swimming events since the 2008 Paralympic Games.

\section{Technological capacitation and the ablenational body politic}

In the UK, double leg amputee athlete Richard Whitehead is one of the most celebrated and featured athletes within Paralympic coverage: his disability classification and event constitute over $50 \%$ of total coverage and he becomes hyper-visible and narrated through promotional films and wider promotional extracts. Indeed, promotional athlete films are emblematic of a preference for a 'prosthetic aesthetic' (Tamari 2017); medal winning British athletes who use mobility enhancing technologies being preferred by $\mathrm{C} 4$ across its promotional films. The extent of the visibility of his body is revealed in a closer reading of one of the films. ${ }^{4}$ In the opening 
image, the focus is on Whitehead's technologically capacitated body, revealing his tall muscular physique enhanced with, and centered on, carbon fibre prosthetics. Against a backdrop of an athletics track, the immediacy and visibility of his body is presented as a silhouette seemingly invoking a vision of cyborgification through the demonstration of an embodiment of technological capacitation- not merely an extension of - that serves to all but disguise debility, subsumed under a representation that approximates functional ableism and a cyborgian aesthetic.

The functionality of his body is corroborated by an inspirational narrative grounded in a discourse of bodily ability. As Whitehead is depicted beginning his exercise routine, his prosthetics central to the image, the film explains Whitehead's motivation for sporting success and his perception of 'what you can and can't do as an amputee' inspired by Canadian amputee Terry Fox who famously ran ultra-marathon distances on his prosthetic limb. On the surface, Whiteheads account presents an individualised story of an incredible sporting effort, one that can be mapped onto the dominant 'supercrip' narrative isolated from wider issues of struggle and dependency and where exceeding disability is posited as a simple act of motivation (Kafer 2013). Whilst operating to make disability visible and provide a highly affective encounter for audiences, expected given the role of the promotional athlete films (Pullen et al. 2018), it does far little to 'challenge' dominant disability narratives. Indeed, whilst this type of coverage reinforces the discursive logic of the 'supercrip', an alternative reading, given the visual embodiment of technological capacitation, is more problematically indicative of ablenationalism (Mitchell and Snyder 2015). That is, Whiteheads story-interpellated with that of Terry Fox-told through his successfully, able-disabled capacitated and exceptional body narrates a story that connects with a wider and much less exceptional disability discourse, for instance, through the rhetoric that assumes his level of privileged capacitated ability can be 
extrapolated to all amputees allowing for the same degree of ablement. Clearly, Whitehead is not like 'all amputees', but his position within this (albeit ephemeral) celebrated cultural space allows for his capacitated body to do 'representational work' on behalf of disability. Indeed, and further indicative of ablenationalism, Whitehead and Fox's bodies are highly nationalised bodies, both visibly depoliticised from discourses of race, ethnicity, class and socio-economics, and narratively isolated from any reference to structures, power and politics that have enabled their position and bodily capacitation. This further serves important representational ends, comfortably connecting Whiteheads exceptional body to the wider unexceptional disability population, thus rendering possible and intelligible a story of neoliberal inclusivity.

Whitehead's 'nationally normative' disabled body-politic was emblematic of the wider representation of disabled bodies across Paralympic coverage and contours the critique offered by Ellis and Goggin (2017) of Oscar Pistorius. Indeed, and whilst not the principal focus of this study, this nationally normative disabled body was implicitly white. This in and of itself is perhaps not overly surprising; only 7\% of Paralympics GB athletes in 2016 were of black and minority ethnic (BME) origin (relational to $13 \%$ of the UK population who identified as BME in the 2011 census, and, over one third of all Team GB (able bodied) Olympic medals in 2012). As with discussions of able-bodied sporting cultural products (including NASCAR, the National Football League in the United States, and sport film, see e.g. Kusz 2007, Newman and Giardina 2010, Talley and Casper 2007) there are certainly questions here over how the Paralympics projects and normalises whiteness, and with respect to how an assumed, naturalised and racialized ablenational disabled body politic intersects with the gendered, technologized and neoliberal aesthetic that enables capacitation and inclusion. As is argued in the case of Pistorius, the sporting body is a projection of the national imaginary, not simply through the dominant embodiment of nationally normative characteristics, but in the extent, it 
reflects, on the surface, the socio-political narrative of the country. For South Africa, prior to his conviction, Pistorius offered a symbol of the post-apartheid - "Rainbow" nation - of South Africa (Ellis and Goggin 2017). For Whitehead, this is the story that connects with neoliberal equality discourses, presenting the UK as an inclusive nation for all people with disabilities. However, it can be argued that such representations are indicative of an uneven distribution of resources at the intersection of disability, race and ethnicity, where, following Puar (2017), some bodies deemed disabled are always debilitated by virtue of their position within identity discourses in an economy of structural inequalities. In contrast, the white privileged disabled bodies on display through Paralympic coverage, epitomised in the representation of Whitehead, are bodies where the logics of ableism and aesthetics appear 'naturally synonymous' but are in fact produced by capacitation that structure forms of neoliberal embodiment against the neoliberal coordinates for the ongoing control - and inclusion - of a neoliberal body-politic (Mitchell and Snyder 2015).

For us, we read this coverage under the auspices of an ablenationalism that works to proffer disability by disguising it under debility and the structural conditions that serve to sustain forms of disability exclusion that simultaneously cultivate the grounds of inclusion. In this sense, this text serves as a powerful cultural script, that when combined with the affective national celebrity sporting economy, offers a privileged, powerful, potent and pedagogic disability body-politic; one devoid of the very apparatus that enable its positionality and capacitation.

It is perhaps the focus on the prosthetic within the text — and the Paralympics writ large - that foster technological capacitation. As the film continues, Whitehead is seen sat on the athletics track using a tool to fit and adjust the position of glossy carbon fibre cheetah legs. Whilst the embodied nature of technological integration constructed through the opening image is 
momentarily disrupted with a glimpse of Whitehead without his prosthetic legs - his stumps clearly in view - the image quickly turns to Whitehead sliding his prosthetics on his stumps, demonstrating the transformative ability that technological capacitation for certain forms of debilities provides. The demonstration of control, adjustment and ultimate transformation through his prosthetic begins to signify and re-frame relations of power in and through ablest (functionality), masculinist (control) and neoliberal (aesthetic) logics that invest his body with the markers of successful citizenship (Mitchell and Snyder 2015). Through cultivating his body as an ablenational symbol, the text further mobilises the extent through which his cyborgian body suggests a 'carbon fibre' masculinisation; exacerbated in both form and feature with lightweight, slim-line, and technologically advanced form of prosthetic designed to capacitate for increased functionality in the hyper-ableist, hegemonic masculinised space of sport.

The articulations between inclusion, capacitation and masculinity become most visible toward the end of the film where he is depicted lying on a physiotherapist bed. In this shot, his naked torso is centred, slightly flexed, and with his physicality on display positioned as per that of a posed male model torso so ubiquitous in popular cultural depictions of a body for consumption. Most ubiquitous to able bodied sport, this representational form is symptomatic of the contemporary mediatized 'gaze' where visual consumption propagated on neoliberal affective mechanisms shifts the focus of the sporting body from action (doing) to spectacle (consuming) providing, at least for the male body, polysemic forms of sexualised presentation (Miller 2001). On the surface, this explicit and ableist masculinisation of Whitehead body may seem in contradistinction to the representational history of the gendering of the disabled body, symptomatic of the effort made by $\mathrm{C} 4$ to represent disability in ways that 'challenge' dominant stereotypes, and demonstrating the comfortable articulation of, what Miller (2001) refers to as the 'sportsexed' body, within specific technological capacitated debilitated bodies. Yet, 
Whiteheads ablenational body makes it palatable to able-bodied audiences, doing less to disrupt dominant disability modes than effectively serving to reinforce the neoliberal inclusivity of an 'normatively' gendered form of disability. This palatability, in the form of a ‘conspicuous display' of muscular cyborgian athleticism (Mitchell and Snyder 2015), is arguably a disability body-politic constituted and configured within the logics of a neoliberal, idealised, able-embodiment.

\section{The Debilitated Disabled}

In the above passage, we read the representation of Whitehead's body as representative of a wider Paralympic spectacle that serves as an 'affective epidemic' (Grossberg 2014). Our point is not to suggest this film in and of itself is a site for the expressive re-enactment of normalized, highly politicized, affective investments that normalizes the affective-ideological presumptions of the prevailing neoliberal consensus. However, as part of a wider logic of Paralympic spectacle, we point to how popular Paralympic spectacle, and sport more generally (see Andrews and Silk 2018), has been co-opted by hegemonic political formations so as to normalize an ableist, and supposedly inclusive, neoliberal disability body politic. In this regard, celebrated and spectacularised ablenational parasport bodies act as seductive agents of neoliberal micro-governance which idealize particular ways of being in the world, while demonizing others (Andrews and Silk 2018). As with Whitehead, we do not suggest that one short promotional film - this one centred on Ellie Simmonds, the UK 'poster girl' of the London 2012 Paralympics, and one of the most successful Paralympic swimmers (holding a World record in the 400 metre freestyle swimming event and winning numerous Parasport medals) — does, in and of itself, act as a seductive, spectacular and affective technology of neoliberal governance. We do however, suggest that the film focussed on Simmonds is 
indicative of a wider 'logic' inherent in contemporary Paralympic representations that position certain bodies as abject or antithetical to the transformative technological capacitation of certain forms of debilities and does little to challenge the neoliberal inclusivity of an efficiently and normatively gendered form of disability.

Like Whitehead, Simmonds is an exceptional athlete, whose sport (along with track and field athletics) tends to dominate Paralympic coverage. This is not least due to a presumed understanding by audiences given similarities to able-bodied events that tend to dominate Olympic schedules. Indeed, in the wider project which focussed on coverage during Rio 2016, taken together, swimming and track and field athletics amounted for over $50 \%$ of coverage, yet, the relative visibility of Simmonds disability classification, despite her success from London 2012, accounted for approximately $25 \%$. These 'logics' were further manifest in the athlete promotional films: Simmonds was far less visible in the film focussing on her when compared with films focussed on female para-athletes who use mobility enhancing technology. The comparative difference in visibility is telling in and of itself; in the passage below, we unpack the nuances and subtle yet significant differences in representation to the vignette above, so as to tease out the articulations between technological capacitation, efficient and normative gendered forms of disability, and the guise of neoliberal 'inclusivity'.

In direct contradistinction to the centering of Whitehead's body in the opening image of his film, Simmonds is depicted diving into the swimming pool, her body only briefly in view before being largely hidden under the water. This image oscillates between an image of her sat on a stool, dressed in dark clothing against a non-descript backdrop, as she narrates her disability story. She begins detailing how 'as a child [she] wanted to win everything'; a statement that underpinned the wider rhetoric in coverage of Simmonds. For instance, and 
despite being 21 years of age at the time of Rio Paralympic Games, a number of rhetorical devices are used throughout the commentary, such as 'still only 21' and 'the youngest of five children' [emphasis added], that signify a process of infantilization (Bruce 2013). This discourse underpins the promotional film, as she continues, highlighting how '.. if there was something really high, I would always find a way of getting it without asking anyone... a way to achieve something without asking anyone for help'. Consistent with normative disability narratives, $a$ success story prevails, structured on a wider and general story of 'overcoming' where disability is positioned as an individual problem for the self to be exceeded in pursuit of independence (Jackson et al. 2014). Like Whitehead this story is suggestive of a problematic perception of disability as an isolated problem and remains consistent in unhinging disability from any social and structural facets of power. Yet, it is remarkably different to Whiteheads story of success born out of the legacy of his technologically capacitated marathon running hero that neatly maps onto the narrative logics of the supercrip. Indeed, Simmonds story is one of unexceptional disability — despite her sporting success—and lacks the affective dimension that underpins stories narrated on 'supercrip' logics. This is important in understanding contemporary disability body politics, for, following Featherstone (2010), affect, or in other words, 'intensities that are palatable' (p.199) and aesthetics work as two sides of the same coin in the construction of visual representations, mediating 'felt' bodily states (Clough 2008) and cultural consumption that make (some) identities and imaginaries possible (Puar 2017). Affect is thereby central to the biopolitical control of disability - as a way to make possible some disabled bodies in the widening circuits of 'inclusion' and allowing those bodies to do the important 'representational work' (Mitchell and Snyder 2010) in constructing cultural (normative) disability imaginaries. Here then, the narrative of Simmonds disability story, constrained within a largely ambivalent sequence of images, operates to regulate the consumption of her body in diametric opposition to ablenational narratives. 
This affect/aesthetic relationship is further highlighted in the relative hypo-visibility of 'beautification' or 'feminising' of Simmonds in relation to normative forms of feminine body practices. Compounded by production logics that appear to conceal much of her corporeality, this is indicative of a wider historical representation of the female disabled body; the dominant 'gaze' here is one of 'asexual objectification' (Harlan 1988). Simmonds is not represented as part of a spectacularised sexualized/celebrity disability culture endemic to more recent Paralympic Games and which has seemingly promoted the 'sexual objectification' of at least some female Paralympians; this is perhaps especially the case when compared with coverage of Dutch para-athlete Marlou Van Rhijn dubbed the 'blade babe' in commentary and featured on C4's Rio highlights programme, The Last Leg ${ }^{5}$. Indeed, Simmonds small stature presents a material complication for the feminine aesthetic that may, in part, contribute to the infantilization of her body. Representations of people with the condition commonly known as dwarfism have previously mirrored dominant disability tropes; particularly in the case of freak, villain, or childlike dependents (Adelson 2005). Yet, alongside the prosthetic disabled body, the contemporary moment has seen the 'voyeuristic sexual gaze' turn on some male celebrity figures of small stature; one such example is Peter Dinklage who featured in People Magazine's list of 'Sexiest Men’ (See Meeuf 2014).

Whilst this raises further questions as to the polysemy of masculinity in new 'inclusive' disability discourses, it indicates the use of prosthetics as an important signifier of inclusion in the feminine gendered economy and acceptable gendered disabled citizenship. Considering the comparisons made above, we can read prosthetic technology as an aesthetically acceptable surface extension of new potentialities of 'beautification' borne from the ability of successful technological transformation and a feminine politic that meets the demands of neoliberal 
citizenship (Puar 2017). Former USA Paralympian and double leg amputee turned successful fashion model and disability activist is perhaps the most visible example of this form of disability feminine politic (Dolezal 2017, Tamari 2017). Mullins, who owns 12 pairs of prosthetic legs ${ }^{6}$, demonstrates a cyborgian transformation in her feminine identity as an individual project of beautification, demonstrating a set of gender relations where the female cyborg is compatible with, and emblematic of, an emerging neoliberalised post-femininity (Rottenberg 2014) anchored in a form of consumption that responds to the demands of bodily capacity. Unlike Mullins, Simmonds disabled body is unable to successfully meet the demands of neoliberal post-femininity, and thus limited by the increasing 'flexibility' of the postfemininity. Much like Whitehead, the gendering of Mullins and Dutch sprinter Van Rhijn emerge as ultimate ablenational icons; exceptional highly capacitated nationally normative able-disabled bodies included within the cultural industries and who perform 'representational work' through hyper-visibility and advocacy on behalf of all disabilities; ultimately serving as a (false) cultural imaginary of disability inclusion.

In contradistinction, Simmonds is presented in a highly domesticated mode, most telling through the dominant image of her toward the end of the film where she is depicted folding and packing her Paralympic sportswear. A poster on the wall behind her depicts a male actor known for his part in a series of teen fantasy films. Arguably, the poster is a display of Simmonds heteronormativity, the first moment where an identity beyond her disability is signified, however given the context of the image and its place within the wider narrative of the film, its signification is perhaps more indicative of the process of infantilization, further reinforcing the focus on a constructed adolescence consistent with wider stereotypical representations of the female disabled body (cf Leseleuc et al. 2010, Ferri and Gregg 1998). 
In the final passage of the film, Simmonds opens a draw revealing an abundance of Paralympic medals, demonstrating the extent of her Paralympic success. When read in relation to Whitehead, this image is particularly revealing given the relative absence of ablenational representation. Unlike Whitehead, Simmonds's body does not denote the corporeal signifiers of ablenationalism, the hyper-capacitated (and hyper-visible) prosthetic able-disabled, a 'buffed, muscular...technologically enhanced body' (Mitchell and Snyder 2015, p. 56). Instead, her impairment, her infantilization and her hypo-visibility, are suggestive of a body that cannot perform ablenationalism 'representational work' within the exceptional Paralympic (and thus wider disability) success story. Rather, for Simmonds, disability 'success' is affectively mediated in such a way that circumvents the corporeal; a success that is passively represented through her 'doing' as demonstrated by sporting medals, rather than through a 'consuming' of a technological capacitated body. Arguably, in these two distinctly different representations, ideologically, Simmonds body serves the national imaginary, and Whitehead, a body of the national imaginary.

\section{Concluding Thoughts}

We are careful not to claim within this article that the two vignettes we have discussed in and of themselves, as standalone entities, normalize certain forms of disability whilst demonising others (see Pullen et al. 2018). This would of course be presumptive, deny the polysemy of reception and of differing interpretation. Rather, in the context of the much larger project that included elite production interviews, extensive audience engagement, quantitative and qualitative content analysis, we have drawn on these two emblematic broadcast segments so as to enhance our academic appreciation of the representation of Paralympic bodies. The intent has been to build upon extant understandings - ground within a supercrip theoretical axis (see 
e.g. Silva and Howe 2012) of the appropriation, co-option, and mobilization of Parasport as an important, hyper-visible, component of an affective epidemic (Grossberg 2014) that normalizes the affective-ideological presumptions of the prevailing neoliberal consensus: an ableist, and supposedly inclusive, neoliberal disability body politic. Indeed, understanding parasport bodies through a critical cultural studies approach can begin to place Paralympic scholarship in dialogue with new materialist approaches to mediated forms of disability; not simply through a renewed focus on the generative capacities and affective intensities of certain celebrated and valorised forms of disability, but, the extent this is embedded and transmitted through circuits of cultural production that (re-)produce ephemeral - yet very real - disability imaginaries and perceptions. Whilst the discussion has attempted to augment our understandings of the biopolitics of disability / debility, the Paralympic body politic, and how hierarchies of inclusion within biopolitical economies of neoliberalism are sustained, generated and nurtured, we appreciate this is one of the first attempts to hold together such a theoretical assemblage. As such, we would certainly call for additional work that can aid in further unpacking contemporary disability (bio-)politics, the nuances of Paralympic representations, and the potential for new and more inclusive disability imaginaries under the limiting possibilities of ablenationalism.

By way of our tentative contribution to these debates, we have unpacked these vignettesrelational to contemporary representations of celebrated and spectacularised ablenational parasport bodies (in the UK at least) — as part of the seductive apparatus of neoliberal microgovernance suggestive of an emerging ecology of disability-gender relations; a sexualized/celebrity disability culture where the technologicalization of disability (Howe 2011) invests certain disabled bodies with forms of citizenship - a process of ablenationalism (Mitchell and Snyder 2015) - that facilitate some modes of heteronormative gendering for some 
disabled bodies under specific conditions (Garland-Thomson 2017). Holding together contemporary representations of disability through perhaps its most hyper-visible form - the Paralympics - with extant knowledge and recent contributions to disability theorising from Puar (2017) and Mitchell and Snyder (2015), we have been able to offer a more nuanced interpretation of the disabled body politic, suggesting how both hyper- and hypo-visible Paralympic bodies are indicative of a an affective ablenational that privileges certain bodies as 'effectively and normatively' disabled and manifests gendered disability icons that serve the nation ideologically under the guise of inclusion.

In so doing, the representation of Richard Whitehead epitomises a gendered ablenationalism. Through carbon fibre prosthetic technology he is presented as a hyper-capacitated transformative body, the 'buffed, muscular yet technologically supplemented' (Mitchell and Snyder 2015 , p. 56) cyborg body of the national disability imaginary. His increased functionality, form and feature of technological integration and corporeal aesthetics, simultaneously work to manifest a carbon-fibre masculinisation, where his body, and bodies alike, become, palatable 'objects of fascination...[as] vehicles for the ornate display of a conspicuous from of technological consumption' (Mitchell and Snyder 2015) suitable for ablebodied audiences. This is corroborated by affective narrative frames that nourish ablenationalism through highly exceptional and depoliticised disability success that curate his body as a national icon for cultural consumption. Comparatively, Simmonds, who, by virtue of her condition (and form of debilitation), lacks the potential for hyper capacitated forms of technological augmentation, and with this, the capacity for (re-)claiming femininity in an emergent neoliberalised disability body politics in which technological transformation is seemingly deemed central to the feminine politic. As such, Simmonds becomes hypo-visible, represented through dominant disability representations as a body of asexual objectification. 
Indeed, despite her success as a Paralympian, she is regulated via a narrative of infantilization across the coverage, lacking the affective dimensions of ablenational narratives, and remains marginalised in the emerging ecology of gender-disability relations. Whilst the cyborg body is clearly a body marked 'other' through the visible and specific form of technological augmentation, the ablenational form of gendering of these bodies act, paradoxically, to 'naturalise' such a body, both reinforcing the grounds of its inclusion by making it increasingly and affectively knowable within ableist systems.

In sum, and at this conjunctural moment, we can understand the representation of the Paralympics (at least in the UK) as a site of 'national recognition' (Puar 2017, p.70); a particularly powerful and popular space that serves to nourish gendered ablenational representations and narratives through the privileged bodies of highly capacitated nationally normative cyborgs. On the surface this cultivates an illusion of greater, more diverse and inclusive disability representation that seemingly challenge stereotypes. Yet, ablenational frameworks that structure such representations inherently nourish extant neoliberal power structures where the representation of some, selected, normatively gendered disabled bodies is based on the regulated exclusion of others. In this regard, the Paralympics can be understood as another, and we would aver hyper-visible, disability site that engenders the "contradictions of neoliberalism" (Sothern 2007, p. 146) creating a greater disparity between disabled bodies; between those who are folded into the biopolitical vectors for life (Puar, 2017) at the expense of debilitated-disabled bodies deemed redundant against the demands of neoliberal economies and left for 'slow death' (Berlant 2007). Thus, as Paralympic representations aim to normalise disability (see Pullen et al. 2018), they may conversely act to exceptionalise; they not only obscure the conditions that debilitate bodies and make inclusion within and outside of sport tangible, but they reproduce, sustain, nourish and propagate wider conditions of debilitation 
via highly affective but limited mediation of technologically capacitated privileged bodies marketed to the masses under the wider universal category of disability.

\section{Notes}

1. In Stuart Hall's last interview (Jhally, 2016), he described the commercialisation of the London 2012 Olympic and Paralympics as both shocking and horrendous. Hall's point was that lauded commercial entities could oppositionally be read as 'deep enemies'; in the case of the Paralympics for example, a key sponsor was one of the very organisations responsible for managing the means testing of disabled people that restricted access to the disability living allowance.

2. Political processes and strategies include (but are not limited to): the governance of the materiality of life and individual practices through an 'affect economy' (Clough, 2008 p.15); vast webs of population data-gathering mechanisms that aids the development and expansion of market capacities; and a reduction in the 'state' and collective spaces that helps cultivate conditions for increasing corporate exploitation and market expansion.

3. The wider project (AH/P003842/1) integrates elite production interviews with large scale audience interviews and focus groups, archival analysis, public pedagogic forms (including a series of performances / documentary film).

4. Richard Whitehead athlete feature, Rio Paralympic Games 2016. Channel 4. $11^{\text {th }}$ September 1600h. Taken from Box of Broadcasts

https://learningonscreen.ac.uk/ondemand/index.php/prog/0D6F428F?bcast=12247779 $\underline{9}$.

5. See also, https://www.standard.co.uk/sport/other-sports/marlou-van-rhijn-embracingblade-babe-nickname-ahead-of-world-para-athletics-championships-a3579661.html. 
6. Mullins, Aimee. "Aimee Mullins: My 12 Pairs of Legs". TED, 2009, https://www.ted.com/talks/aimee mullins prosthetic aesthetics

\section{References}

Adelson, B., 2005. The lives of dwarfs: Their journey from public curiosity toward social liberation. New Brunswick, NJ: Rutgers University Press.

Andrews, D., and Silk, M., 2018. Sport and neoliberalism: An affective ideological articulation. Journal of popular culture, 51 (2), 511-533.

Balasmo, A.M., 1996. Technologies of the gendered body: Reading cyborg women. London: Duke University Press.

Barnes, C., and Mercer, G., 2010. Exploring disability. Cambridge: Polity Press

Barounis, C., 2009. Cripping heterosexuality, queering able-bodiness: Murderball, Brokeback Mountain and the contested masculine body. Journal of visual culture, 8 (1), 54-75.

Batts, C., and Andrews, D.L., 2011. 'Tactical Athletes': The United States Paralympic Military Programme and the mobilization of the disabled soldier/athlete. Sport in society, 14 (5), 553568.

Berlant, L., 2007. Slow death (Sovereignty, Obesity, Lateral Agency). Critical inquiry, 33 (4), 754-780 
Bertling, C., and Schierl, T., 2008. Contemporary cultures of presence and aesthetics. Sport in history, 28 (1), 39-50

Briant, E., Watson, N., and Philo, G., 2013. Reporting disability in the age of austerity: the changing face of media representation of disability and disabled people in the United Kingdom and the creation of new 'folk devils'. Disability \& society, 28 (6), 874-889.

Brittain, I., and Green, S., 2012. Disability sport is going back to its roots: rehabilitation of military personnel receiving sudden traumatic disabilities in the twenty-first century. Qualitative research in sport, exercise and health, 4 (2), 244-264.

Bruce, T., 2013. Reflections on communication and sport: On women and femininities. Communication \& sport, 1 (1-2), 125-137.

Buysse, J.A.M., and Borcherding, B., 2010. Framing gender and disability: A cross-cultural analysis of photographs from the 2008 Paralympic Games. International journal of sport communication, 3 (3), 208-321.

Cherney, J. L., 2001 'Sexy cyborgs: Disability and erotic politics in Cronenberg's Crash'. In: C. R. Smit and A. Enns, eds. Screening disability: Essays on cinema and disability. Lanham, MA: University Press of America, 165-180.

Claydon, E. A., 2014. Framing the difference(s): Analysing the representations of the body of the athlete in the 2012 Olympics' and Paralympics' official programmes. In: D. Jackson, C. Hodges, M. Molesworth, and R. Scullion, eds. Reframing Disability?: Media, (dis)empowerment, and voice in the 2012 Paralympics. London: Routledge, 79-94. 
Clough, P.T., 2008. The affective turn. Political economy, biomedia and bodies. Theory, culture and society, 25 (1), 1-22

Coffey, A., and Atkinson, P., 1996. Making sense of qualitative data. London: Sage

Crow, L., 2014. Scroungers and Superhumans: images of disability from the summer of 2012: A visual inquiry. Journal of visual culture, 13 (2), 168-181.

Diedrich, L., 2005. Introduction: Genealogies of disability: Historical emergences and everyday enactments. Cultural studies, 19 (8), 649-666.

Dolezal, L., 2017. Representing posthuman embodiment: considering disability and the case of Aimee Milluns. Womens studies 46 (1), 60-75.

Elliot, D., 2003, Moral responsibilities and the power of pictures. In: P. M. Lester, and S. Ross, eds. Images that injure: Pictorial stereotypes in the media. Praeger: London, 7-15.

Ellis, K., and Goggin, G., 2017. Disability, global popular media, and injustice in the trial of Oscar Pistorius. In: E. Ellcessor and K. Kirkpatrick, eds. Disability media studies. New York: NY University Press, 197-222.

Featherstone, M., 2010. Body, Image and Affect in Consumer Culture. Body \& society, 16 (1), 193-221.

Ferri, B. A., and Gregg, B., 1998.Women with disabilities: Missing voices. Women's studies International forum. 21 (4), 429-439. 
Garland-Thomson, R., 2002. Integrating disability, transforming feminist theory. NWSA Journal. 14 (3), 1-32.

Garland-Thomson, R., 2017. Extraordinary bodies: Figuring ohysical disability in American culture and literature. New York: Columbia University Press.

Gerschick, Thomas., 2000. Toward a theory of disability and gender. Signs: Journal of women in Culture and society, 25, 1263-8.

Grossberg. L., 2014. We gotta get out of this place. Popular conservatism and postmodern culture. London: Routledge

Hahn, H., 1988. Can disability be beautiful? Social policy, 18, 26-31.

Haraway, D., 1991. Simians, cyborgs, and women: The reinvention of nature. London: Routledge

Hardin M and Hardin B. (2005). Performance of participation...pluralism or hegemony? Images of disability \& gender in Sports'n Spokes magazine. Disability studies quarterly. 25(4): 11.

Hickey-Moody, A., 2015. Carbon fibre masculinity. Disability and surfaces of homosociality. Angelaki: Journal of the theoretical humanities, 20 (1), 139-153.

Howe, P. D., 2008. The cultural politics of the Paralympic movement: Through the anthropological lens. London: Routledge 
Howe, P.D., 2011. Cyborg and supercrip: The Paralympics technology and the (dis) empowerment of disabled athletes. Sociology, 45 (5), 869-882.

Howe, P.D., and Silva, C.F., 2017. Challenging normalcy: Possibilities and pitfalls of Paralympic bodies. South African journal for research in sport, physical education and recreation, 39 (1-2), 191-204

Jackson, D., Hodges, C., Molesworth, M., and Scullion, R., 2014. Re-framing disability? The media, (dis)empowerment and voice in the London Paralympics. London: Routledge.

Johnson, R., Chambers, D., Raghuram, P., and Tincknell E., 2004. The practice of cultural studies. London: Sage.

Jhally, S., 2016. Stuart Hall: The last interview. Cultural studies. 30 (2), 332-345

Kafer, A., 2013. Feminist queer crip. Indianapolis: Indiana UP.

Kirkup, G., 2000. Introduction to Part One. In: In: G. Kirkup, F. Hovenden, L. lanes, K. Woodward, eds. The gendered cyborg: A reader. London: Routledge, 3-10.

Kurzman, S.L., 2001. Presence and prosthetics: A response to Nelson and Wright. Cultural anthropology, $16(3), 374-87$.

Kusz, K., 2007. From NASCAR nation Pat Tillman: Notes on sport and the politics of white cultural nationalism in post 9/11 America. Journal of sport \& social issues, 31 (1), 77-88. 
Léséleuc, E. de., Pappous, A., and Marcellini, A., 2010. The media coverage of female athletes with disability. Analysis of the daily press of four European countries during the 2000 Sidney Paralympic Games. European journal for sport and society, 7 (3-4), 283-296.

Longmore, J. 2015. Telethons: Spectacle, disability and the business of charity. Oxford: Oxford University Press.

McRuer, R., 2006. Crip Theory: Cultural signs of queerness and disability. New York: New York University Press.

McRuer, R., 2017. Compulsory able-bodiedness and queer/disabled existence. In: L.J. Davis, (ed). The Disability studies reader. London: Routledge, 396-406.

Meeuf, R., 2014. Celebrity body and the meritocracy of the star system: constructing peter Dinklage in entertainment journalism. Journal of communication inquiry, 38 (3) 204-222. Miller, T., 2002. Sportsex. Temple University Press: Philadelphia.

Mitchell, D., and Snyder, S.L., 2010. Introduction: Ablenationalism and the geo-politics of disability. Journal of literary and cultural disability studies, 4, (2), 113-125.

Mitchell, D.T., and Snyder, S.L., 2015. The biopolitics of disability. Neoliberalism, Ablenationalism, and Peripheral Embodiement. Michigan: University of Michigan Press.

Newman, J., and Giardina, M., 2010. Neoliberalism's last lap? NASCAR nation and the cultural politics of sport. American behavioural scientist, 53 (10), 1511-1529. 
Puar, J.K., 2017. The right to maim. debility, capacity, disability. London: Duke University Press.

Pullen, E., Jackson, D., and Silk, M., 2018. Re-presenting the Paralympics: (contest) philosophies, production practices and the hypervisibility of disability. Media, culture \& society, doi: 10.1177/0163443718799399

Pullen, E., Jackson, D., and Silk, M., 2019. (Re-)presenting the Paralympics: Affective nationalism and the "able-disabled". Communication \& sport. doi: $10.1177 / 2167479519837549$

Rottenberg, C., 2014. The rise of neoliberal feminism. Cultural Studies, 28 (3), 418-437.

Schalk. S., 2016. Reevaluating the supercrip. Journal of literary \& cultural disability studies, $10(1), 1757-6466$.

Schell, L. A., and Duncan, M. C., 1999. A content analysis of CBS's Coverage of the 1996 Paralympic Games. Adapted physical activity quarterly, 16 (1), 27-47.

Schell, L.A., and Rodriguez, S., 2001. Subverting bodies/ambivalent representations: media analysis of Paralympian, Hope Lewellen. Sociology of sport journal, 18, 127-135.

Shakespeare, T., 1999. ‘Art and lies? Representations of disability on film'. In: M. Corker, and French. S, eds. Disability discourse. Buckingham: Open University Pres, 164- 172. 
Shakespeare. T., and Watson, N., 1997 Defending the social model. Disability \& society 12 (2), 293-300.

Shildrick, M., 2006. The disabled body, genealogy and undecidability. Cultural studies, 19 (6), $755-770$.

Shuttleworth, R., Wedgewood, N., and Wilson, N.J., 2012. The Dilemma of Disabled Masculinity. Men and masculinities, 15 (2), 174-194.

Siebers, T., 2008. Disability Theory. Ann Arbor, MI: University of Michigan Press.

Silva, C.F., and Howe, P.D., 2012. The (in)validity of supercrip representation of Paralympic athletes. Journal of sport \& social issues. 36 (2), 174-194.

Sothern, M., 2007. "You could truly be yourself if you just weren’t you: sexuality, disabled body space, and the (neo)liberal politics of self-help". Environment and planning: Society and space. 25 (1), 144-159.

Swartz, L., and Watermeyer, B., 2008. Cyborg anxiety: Oscar Pistorius and the boundaries of what is means to be human. Disability \& society. 23 (2), 187-190.

Talley, H., and Casper, M., 2007. A response to the motion picture Talladega Nights: The ballad of Ricky Bobby. Journal of sport \& social issues, 31 (4), 434-439.

Tamari, T., 2017. Body Image and Prosthetic Aesthetics. Disability, Technology and Paralympic Culture. Body \& society, 23 (2), 25-56. 
Tepper, M. S., 2000. Sexuality and Disability: The missing discourse of please. Sexuality and disability. 18 (4), 283-290.

Walsh, A., 2014. Out of the shadows, into the light? The broadcasting legacy of the 2012 Paralympics for Channel 4. In: D. Jackson, C. Hodges, M. Molesworth R. Scullion, eds. Reframing disability?: Media, (Dis)empowerment, and voice in the London Paralympics. London: Routledge, 26-36

Weaving, C., and Samson, J., 2018. The naked truth: disability, sexual objectification, and the ESPN Body Issue. Journal of the philosophy of sport, 45 (1), 83-100.

Weinberg, J K., 1988. Autonomy as a different voice: Women, disabilities, and decisions. In: M. Fine, and A. Asch, eds. Women with disabilities: Essays in psychology, culture, and politics. Philadelphia: Temple University, 269-296 